\title{
Spatial Variability of L-Band Brightness Temperature during Freeze/Thaw Events over a Prairie Environment
}

\author{
Alexandre Roy ${ }^{1,2,3, *}$, Peter Toose ${ }^{4}(\mathbb{D})$, Chris Derksen ${ }^{4}$, Tracy Rowlandson ${ }^{5}$, Aaron Berg ${ }^{5}$, \\ Juha Lemmetyinen ${ }^{6}$, Alain Royer ${ }^{1,2}$, Erica Tetlock ${ }^{7}$, Warren Helgason ${ }^{8}$ and Oliver Sonnentag ${ }^{3}$ \\ 1 Centre d'Applications et de Recherches en Télédétection (CARTEL), Université de Sherbrooke, \\ 2500 boul. Université, Sherbrooke, QC J1K 2R1, Canada; alain.royer@usherbrooke.ca \\ 2 Centre d'Études Nordiques, Université Laval, Québec, QC G1V 0A6, Canada \\ 3 Département de Géographie, Université de Montréal, Montréal, QC H2V 2B8, Canada; \\ oliver.sonnentag@gmail.com \\ 4 Climate Research Division, Environment and Climate Change Canada, Toronto, ON M3H 5T4, Canada; \\ peter.toose@canada.ca (P.T.); chris.derksen@canada.ca (C.D.) \\ 5 Department of Geography, University of Guelph, Guelph, ON N1G 2W1, Canada; \\ trowland@uoguelph.ca (T.R.); aberg@uoguelph.ca (A.B.) \\ 6 Finnish Meteorological Institute, FI-00101 Helsinki, Finland; Juha.Lemmetyinen@fmi.fi \\ 7 Environment and Climate Change Canada, Sasktoon, SK S7N 5A9, Canada; erica.tetlock@gmail.com \\ 8 Civil, Geological and Environmental Engineering, University of Saskatchewan, \\ Saskatoon, SK S7N 5A9, Canada; warren.helgason@usask.ca \\ * Correspondence: alexandre.r.roy@usherbrooke.ca; Tel.: +1-81-9574-6768
}

Received: 30 May 2017; Accepted: 22 August 2017; Published: 29 August 2017

\begin{abstract}
Passive microwave measurements from space are known to be sensitive to the freeze/thaw $(\mathrm{F} / \mathrm{T})$ state of the land surface. These measurements are at a coarse spatial resolution $(\sim 15-50 \mathrm{~km})$ and the spatial variability of the microwave emissions within a pixel can have important effects on the interpretation of the signal. An L-band ground-based microwave radiometer campaign was conducted in the Canadian Prairies during winter 2014-2015 to examine the spatial variability of surface emissions during frozen and thawed periods. Seven different sites within the Kenaston soil monitoring network were sampled five times between October 2014 and April 2015 with a mobile ground-based L-band radiometer system at approximately monthly intervals. The radiometer measurements showed that in a seemingly homogenous prairie landscape, the spatial variability of brightness temperature $\left(\mathrm{T}_{\mathrm{B}}\right)$ is non-negligible during both frozen and unfrozen soil conditions. Under frozen soil conditions, $T_{B}$ was negatively correlated with soil permittivity $\left(\varepsilon_{G}\right)$. This correlation was related to soil moisture conditions before the main freezing event, showing that the soil ice volumetric content at least partly affects $\mathrm{T}_{\mathrm{B}}$. However, because of the effect of snow on L-Band emission, the correlation between $\mathrm{T}_{\mathrm{B}}$ and $\varepsilon_{\mathrm{G}}$ decreased with snow accumulation. When compared to satellite measurements, the average $\mathrm{T}_{\mathrm{B}}$ of the seven plots were well correlated with the Soil Moisture Ocean Salinity (SMOS) $\mathrm{T}_{\mathrm{B}}$ with a root mean square difference of $8.1 \mathrm{~K}$ and consistent representation of the strong $\mathrm{F} / \mathrm{T}$ signal (i.e., $\mathrm{T}_{\mathrm{B}}$ increases and decreases when soil freezing and thawing, respectively). This study allows better quantitative understanding of the spatial variability in L-Band emissions related to landscape $\mathrm{F} / \mathrm{T}$, and will help the calibration and validation of satellite-based F/T retrieval algorithms.
\end{abstract}

Keywords: L-Band; spatial variability; soil permittivity; snow density; freeze/thaw; SMOS 


\section{Introduction}

The freeze/thaw $(\mathrm{F} / \mathrm{T})$ state plays a crucial role in biogeochemical cycling [1,2], vegetation growth [3], permafrost evolution [4] and hydrology [5,6]. The strong dielectric contrast between ice and water at L-Band passive microwave frequencies $(\approx 1.4 \mathrm{GHz}[7])$ allows for monitoring of global $\mathrm{F} / \mathrm{T}$ processes using data from passive microwave L-Band satellite missions. Soil F/T processes have been observed using recent passive L-Band missions including: the National Aeronautics and Space Administration (NASA) Satellite de Aplicaciones Cientificas (SAC-D) Aquarius mission ([8]; 2011-2015), the European Space Agency Soil Moisture Ocean Salinity (SMOS) mission ([9]; 2011-present), and the NASA Soil Moisture Active Passive (SMAP) mission ([10]; 2015-present). However, satellite passive microwave (PMW) observations generally have a coarse spatial resolution at L-Band (nominal resolution of about $40 \mathrm{~km}$ ) and spatial heterogeneity within PMW pixels limits the development and validation of $\mathrm{F} / \mathrm{T}$ retrieval algorithms [11]. At these spatial scales, different ground cover components, including water bodies and vegetation types, can interfere with the soil $\mathrm{F} / \mathrm{T}$ signal. Recent studies also showed that snow density significantly impacts the L-Band signal in winter $[12,13]$. Therefore, ground-based radiometers are used to better understand and isolate the sub-pixel contributions to the F/T signal [12-14].

Paradoxically, one of the limitations related to the use of ground-based radiometer measurements is our capacity to translate these measurements at the plot scale to the satellite-borne sensors, where the large footprint combines large landscape variability within one observation. For example, Wigneron et al. [15] showed that despite the relatively large number of ground-based measurements in support of the development and improvement of the SMOS soil moisture (SM) retrieval algorithms, the operational algorithm remains relatively simple compared to all the knowledge that comes from these ground-based observations. One of the challenges is to translate small radiometer footprints $(\approx 2 \mathrm{~m})$ with homogenous surfaces and site specific conditions, to the more heterogeneous footprint of satellite observations. Hence, a better understanding of the spatial variability in L-Band emissions within a pixel of about $40 \mathrm{~km}$ of nominal resolution could help apply the ground-based radiometer observations to satellite-borne applications, but also inform ground-based radiometer campaigns how to optimize the data gathering for satellite-scale algorithm calibration and validation. This issue is true for SM retrieval at L-Band (including algorithm development and calibration/validation e.g., [16]), but can also be applied to other passive microwave based retrievals of snow water equivalent $[17,18]$ and soil freeze/thaw status [3,9].

This study aims to (1) quantify the spatial variability of L-Band emissions during the 2014-2015 $\mathrm{F} / \mathrm{T}$ season (fall, winter and spring) in a prairie environment from ground-based radiometer measurements recorded across the Kenaston/Brightwater Creek Soil Monitoring Network (KSMN), SK $[19,20]$; (2) link that spatial variability to measured soil and snow properties; and (3) compare that spatial variability to satellite-scale SMOS observations. Between October 2014 and April 2015, seven distributed plots across a single SMOS pixel were visited five times with a mobile ground-based L-Band radiometer system. This paper first describes the ground-based L-Band radiometer dataset gathered during this campaign. The measured $\mathrm{T}_{\mathrm{B}}$ are compared to an in situ soil monitoring network dataset and snow measurements gathered during the campaign. The observed spatial variability of $\mathrm{T}_{\mathrm{B}}$ is then compared to spaceborne SMOS observations, before discussing the implications of using L-Band ground-based radiometers for the calibration and validation of satellite-based $\mathrm{F} / \mathrm{T}$ algorithms.

\section{Method}

\subsection{Soil Monitoring Network Measurements}

Between October 2014 and April 2015 the KSMN $\left(51.4^{\circ} \mathrm{N} ;-106.4^{\circ} \mathrm{W}\right)$ was visited on five occasions (19-20 October, 10-12 November, 9-10 December, 11-13 January, 12-13 April), to acquire mobile ground-based L-Band radiometer measurements. The KSMN [19] is a densely instrumented site across a region of approximately $30 \mathrm{~km} \times 30 \mathrm{~km}$ for SM monitoring in a prairie environment (Figure 1). 
The network is jointly operated by three different organizations: Agriculture and Agri-Food Canada (AAFC), Environment and Climate Change Canada (ECCC), and the University of Guelph. The KSMN site was visited at seven different plots with the mobile ground-based L-Band radiometer system. Each radiometer measurement plot within the KSMN was close to a permanently installed soil and meteorological monitoring station (see Section 2.2). At each soil station, four Steven's Hydra Probes II (Stevens Water Monitoring Systems, Inc., Portland, OR, USA) for volumetric SM measurements were installed horizontally, centred at depths of $5 \mathrm{~cm}, 20 \mathrm{~cm}$ and $50 \mathrm{~cm}$, with the fourth probe installed vertically integrating measurements between $0 \mathrm{~cm}$ and $5.7 \mathrm{~cm}$ below the ground surface. The Hydra Probe measures the soil relative real permittivity $\left(\varepsilon_{\mathrm{G}}\right)$ at $50 \mathrm{MHz}$. Using the measured $\varepsilon_{\mathrm{G}}$, volumetric soil moisture (SM; \%) was calculated based on calibration made at each station [21]. The meteorological measurements were recorded at 30-min intervals. In addition to the Hydra Probe soil measurements, air temperature (HMP45C, Campbell Scientific, Logan, UT, USA) and snow depth using an acoustic distance sensor (SR-50AT, Campbell Scientific) were measured at six of the seven plots.

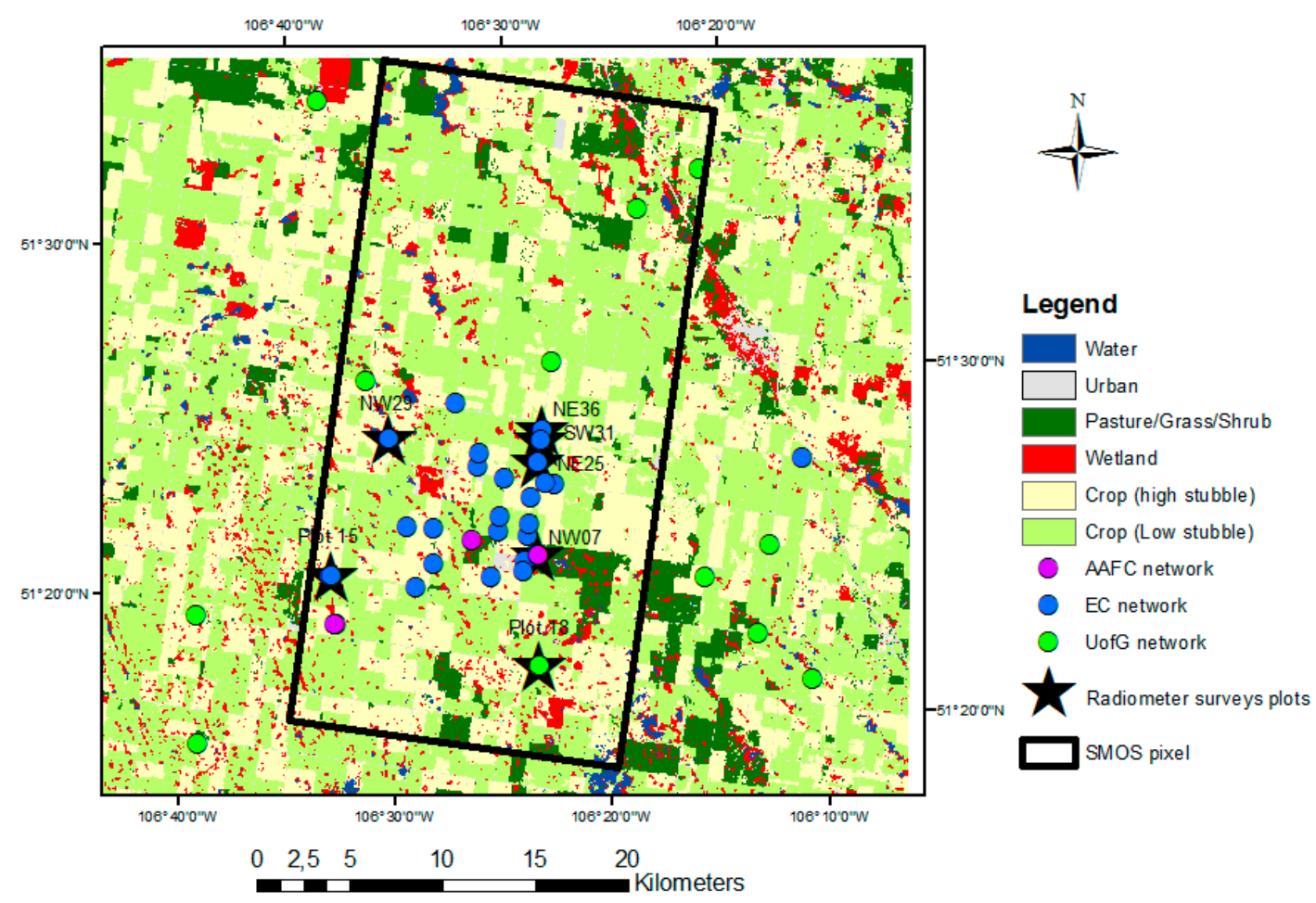

Figure 1. The location of the discrete radiometer and snow survey measurement plots within the Kenaston/Brightwater Creek Soil Monitoring Network (KSMN).

\subsection{Distributed L-Band Measurements}

L-Band measurements at the seven monitoring plots were acquired by a surface-based, hyperspectral, 385 channel, dual polarization, L-Band Fourier transform, radio frequency interference (RFI) detecting radiometer (Radiometrics Corporation ${ }^{\odot}$, Boulder, $\mathrm{CO}, \mathrm{USA}$ ) with a frequency range from 1400 to $\approx 1550 \mathrm{MHz}$ (see [22] for a complete description of the instrument). For the present campaign, the radiometer system was mounted on a mobile manual forklift in order to be moved between plots, with the ability to adjust the height above ground to a standard acquisition height of $2.75 \mathrm{~m}$ above the surface at each measurement plot. The integration time of the radiometer was set to acquire 1 measurement every $\approx 3.9$ s for all 385 channels at each polarization [22].

Toose et al. [22] developed a method to remove RFI contamination. To find an RFI-free $T_{B}$ value representative of the observed spectrum, a 3rd order polynomial of sort-rank versus $\mathrm{T}_{\mathrm{B}}$ is calculated, and the 2 nd derivative of the slope of this cubic polynomial is derived. The RFI-free $T_{B}$ value of the 
scene is the $\mathrm{T}_{\mathrm{B}}$ at the inflection point where the 2nd derivative transitions from negative to positive. During the campaign (see also [13]), 16 three-point calibrations were conducted to calibrate the radiometer including the measurements of sky at zenith (estimated at $\approx 5 \mathrm{~K}:[12,23]$ ), an ambient black body target and a heated warm black body target $(\approx 340 \mathrm{~K})$. Independent sky and calibration target measurements (91 in total, including 21 taken within the KSMN), show that the mean absolute error of the calibration accuracy (MAE) was between 1.0 and $1.5 \mathrm{~K}$ over the course of the entire campaign [22].

The seven distributed radiometer plots were located within a single SMOS pixel (Figure 1). The measurement locations were chosen to characterize the satellite-scale spatial variability in the radiometric signal during different stages of freeze-up and thaw over different fields with varying vegetation, SM, soil texture, and snow accumulation. To assist in the upscaling of these measurements from point-scale to satellite-scale, the land cover within the SMOS pixel was determined using the 2014 AAFC annual crop inventory [24]. The results of this $30 \mathrm{~m}$ land cover classification (produced from analyzing a time series of Landsat- 8 and Radarsat-2 imagery) was simplified by combining the specific land cover classes into more general categories that include the following major land cover classes within the SMOS pixel: cropland, pasture, wetlands, urban and water (Table 1). The SMOS pixel is mainly composed of crops $(83.1 \%)$, wetlands $(6.1 \%)$ and pasture $(4.6 \%)$. The specific cropland classes were further subdivided into two classes (high vs. low stubble; $34.5 \%$ and $49.1 \%$, respectively) with similar post-harvest crop residue characteristics. Cereal crops tend to have tall and robust crop residue and thus were grouped into the high stubble class along with other classes with a standing vegetation height of at least $10 \mathrm{~cm}$. The oilseed and pulse crops tend to have much less residue, which may also break down during threshing [25], and thus were grouped into the low stubble class along with bare soils. These two contrasting stubble heights are known to influence the amount of snow retention within agricultural fields, with deeper snow (and hence greater soil insulation) present in fields with taller stubble [26].

Table 1. Ground-based radiometer measurement plots within the KSMN and their measured soil properties (SM = soil moisture, $\%$; $\varepsilon_{\mathrm{G}}=$ soil permittivity, unitless; RMS = soil surface roughness root mean square height) during the visit at $5 \mathrm{~cm}$ (see Figure 1).

\begin{tabular}{ccccccccc}
\hline Plot & Land Cover Class & Stubble Height & SM Oct. & SM Apr. & $\varepsilon_{\mathrm{G}}$ Nov. & $\varepsilon_{\mathrm{G}}$ Dec. & $\varepsilon_{\mathrm{G}}$ Jan. & RMS (m) \\
\hline NE25 & Crop & high & 0.19 & 0.22 & 7.31 & 7.34 & 6.32 & 0.062 \\
NW07 & Pasture & - & 0.22 & 0.21 & 3.89 & 6.76 & 4.59 & 0.084 \\
NW29 & Crop & low & 0.26 & 0.32 & 7.80 & 7.97 & 5.49 & 0.039 \\
NE36 & Crop & high & 0.27 & 0.34 & 8.73 & 8.11 & 6.84 & 0.055 \\
Plot18 & Crop & high & 0.24 & 0.19 & 10.05 & 10.03 & 8.62 & 0.040 \\
SW31 & Crop & low & 0.18 & 0.35 & 6.43 & 6.52 & 6.10 & 0.020 \\
Plot15 & Grass & - & 0.34 & 0.22 & 11.62 & 8.42 & 8.42 & 0.035 \\
\hline
\end{tabular}

The radiometer plots were flagged to ensure consistent measurement locations and three adjacent (2.5 m spacing) L-Band radiometer measurements were recorded at four incidence angles (30-40-50-60 $)$ during each plot visit. The set of adjacent radiometer measurements were conducted to gain a sense of the plot-scale variability in observed brightness temperatures $\left(\mathrm{T}_{\mathrm{B}}\right)$ present within each field. Careful positioning of the radiometer ensured that the field-of-view was consistent for the entire campaign, reducing the possibility that observed $\mathrm{T}_{\mathrm{B}}$ differences were due to positional errors. At every plot, terrestrial-based Light Detection and Ranging (LiDAR) scans were conducted in October and April (pre- and post-snow), to obtain a quantitative measurement of soil surface roughness, which influences the microwave emissivity of the surface [27]. The soil surface roughness parameter root mean square height (RMS) was calculated based on the approach of [28]. The October and April calculated RMS heights were very similar $\left(r^{2}=0.93\right)$, and thus, the average values of both scans were utilized for each plot.

To identify the variability in $\mathrm{T}_{\mathrm{B}}$ across the soil monitoring network and within one SMOS pixel (see Section 2.4), the average of the three adjacent L-Band radiometer measurements were calculated for each incidence angle $(\theta)$ at each field plot $(p)$ for each visit $\left(T_{B p, \theta}\right)$. To upscale the ground-based measurements for direct comparison with the SMOS data (see Section 2.4), the averaged $T_{B}$ were 
processed using two different methods: (1) the arithmetic average of all seven field plots $\left(T_{B-R a d, \theta}\right)$ was calculated for each monthly visit:

$$
T_{B-R a d, \theta}=\frac{1}{N} \sum_{p} T_{B} p, \theta
$$

where $N$ is the number of sites. (2) a land cover-weighted average of the radiometer measurements. This method calculated the land cover-specific average measurement, and weighted $(W)$ this average by the land cover proportion found within the SMOS pixel $\left(T_{B-R a d-W, \theta}\right)$,

$$
T_{B-\operatorname{Rad}-W, \theta}=\sum_{i}\left(\frac{1}{N_{i}} \sum_{p_{i}} T_{B} p, \theta\right) \cdot F_{i}
$$

where $i$ is the land cover where radiometer measurements were acquired (e.g., high stubble crop [ $\left.N_{i}=3\right]$, low stubble $\left[N_{i}=2\right]$ crop and pasture [ $\left.N_{i}=1\right]$; see Table 1) and $\mathrm{F}$ is the fraction of each class. Because measurements were acquired only within three land cover classes, $\mathrm{F}$ is calculated based only on these three classes, with fractions increasing to absorb the land cover types with low representation. The new land cover fractions are: Crop, high stubble $=0.38$, Crop, low stubble $=0.54$, Pasture $=0.08$. Also, Plot15 (grass) is underrepresented in the SMOS pixel; it was removed from the $T_{B-R a d-W, \theta}$ calculations.

\subsection{Snow Measurements}

Comprehensive snow surveys were conducted in December, January and February at the seven radiometer plots in the KSMN, including snow pit measurements to document profiles of snow temperature and density $\left(\rho_{\mathrm{s}}\right)$ for the major snow layers within the pack. The density was measured using a $100-\mathrm{cm}^{3}$ density cutter, and samples were weighed with a digital scale with an accuracy of $\pm 0.1 \mathrm{~g}$. The snow and soil temperature were measured with a digital temperature probe $\left( \pm 0.1^{\circ} \mathrm{C}\right)$. In addition to snow pit measurements, distributed snow depths surveys, using a GPS enabled Magna Probe $^{\mathrm{TM}}$, were conducted to capture the range of snow depths in the vicinity of the plot with transects $(\approx 100 \mathrm{~m}$ in length), and by measuring snow depth grids $(\approx 10 \mathrm{~m} \times 20 \mathrm{~m})$ at $\approx 1 \mathrm{~m}$ spacing.

\subsection{SMOS Observations}

The ground-based measurements were compared with SMOS $\mathrm{T}_{\mathrm{B}}$ from the Level 3 brightness temperature product (L3TB version 3.0) available on the Centre Aval de Traitement des Données SMOS (CATDS) website (http:/ / www.catds.fr/sipad). The Level $3 \mathrm{~T}_{\mathrm{B}} \mathrm{S}$ are a reconstructed daily global $\mathrm{T}_{\mathrm{B}}$ at top-of-the-atmosphere product, arranged by incidence angle values, in full polarization. It includes all brightness temperatures acquired that day, transformed to a ground polarization reference frame ( $\mathrm{H}$ and $\mathrm{V}$ polarization), binned and averaged into fixed angle classes [29]. SMOS crosses the equatorial node at 06:00 LT during the ascending pass and 18:00 LT during the descending pass.

Variations in the angular profiles related to different errors in the SMOS measurements (including RFI, radiometric noise, $\mathrm{T}_{\mathrm{B}}$ reconstruction) have been observed in other studies [29]. Hence, a smoothing of the angular profiles was performed by applying a best fit 2nd polynomial function on SMOS brightness temperature $\mathrm{V}$ - and H-polarization ( $\mathrm{T}_{\mathrm{BV}}$ and $\mathrm{T}_{\mathrm{BH}}$, respectively) measurements. To assure the robustness of the fit, it was performed only if at least seven angular observations were available. Otherwise, the data were discarded. From the fit, the brightness temperatures of SMOS ( $\mathrm{T}_{\mathrm{B}-\mathrm{SMOS}}$ ) were re-calculated for the same incidence angle as the ground-based radiometer observations $\left(30-40-50-60^{\circ}\right)$. 


\section{Results}

\subsection{Site Meteorology and Snow Measurements}

The air temperature $\left(\mathrm{T}_{\text {air }}\right)$ remained above $0{ }^{\circ} \mathrm{C}$ for the majority of October with only a few nights falling below freezing. The warm $\mathrm{T}_{\text {air }}$ resulted in $5 \mathrm{~cm}$ soil temperature $\left(\mathrm{T}_{\text {soil }}\right)$ remaining unfrozen for the entire month (Figure 2). The primary freeze event occurred on 7 November when $\mathrm{T}_{\text {air }}$ dropped below $-15^{\circ} \mathrm{C}$ and soil at $5 \mathrm{~cm}$ froze except for Plot15, where the soil froze on 10 November. Some ephemeral snow accumulation began at the end of October, but it should be noted that the noisy snow depth signal present in Figure 2 at plot NW07 during October and April is related to the presence of tall grass and shrubs found within the pasture land cover and is not associated with actual snow accumulation. In addition, the very small amounts of snow reported at all sites in April and May are an artifact of soil frost heave and the subsequent change in the reference background height of the soil, and therefore does not represent snow on the ground. The first significant snowfall occurred on 28 November, depositing approximately $10 \mathrm{~cm}$ of snow. During the winter, several melt events occurred when $\mathrm{T}_{\text {air }}$ exceeded $0{ }^{\circ} \mathrm{C}$, although soil temperatures remained below $0{ }^{\circ} \mathrm{C}$. During the coldest winter periods, a large amount of variability in $\mathrm{T}_{\text {soil }}$ at $5 \mathrm{~cm}$ across all plots was observed (Figure 2). This variability is likely due to variability in snow depth (wind redistribution is a key process in this prairie environment; Fang and Pomeroy, 2009). Plot15 and Plot18 had the warmest $\mathrm{T}_{\text {soil }}$ and the corresponding deepest snow depths. The snow began to melt in mid-March, at which point the $\mathrm{T}_{\text {soil }}$ at $5 \mathrm{~cm}$ began to fluctuate around $0{ }^{\circ} \mathrm{C}$, before remaining above $0{ }^{\circ} \mathrm{C}$ during the day from the end of March onwards. Table 2 summarizes the plot/soil condition as observed during the five radiometer and snow survey visits.

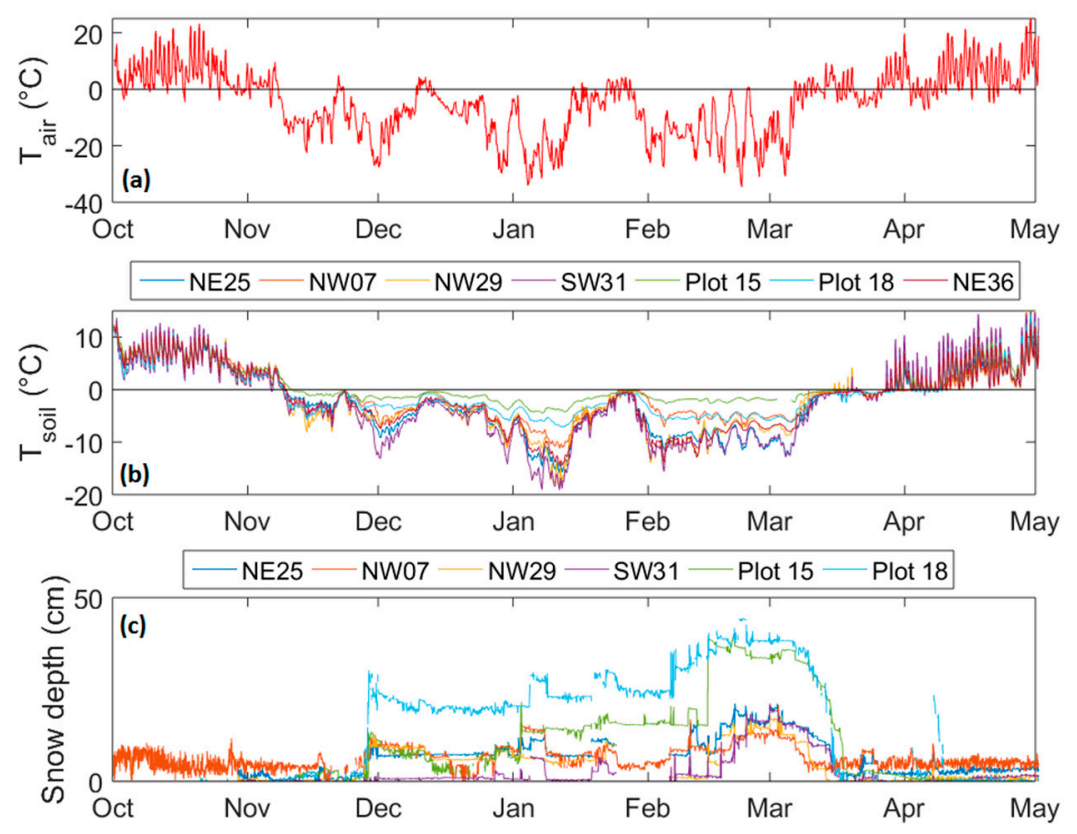

Figure 2. Meteorology at the seven stations across the study domain for each month from October 2014 to March 2015. (a) mean air temperature $\left(\mathrm{T}_{\text {air }}\right)$; (b) soil temperature $\left(\mathrm{T}_{\text {soil }}\right)$ at $5 \mathrm{~cm}$ and (c) automated snow depth at 5 stations. $\mathrm{X}$-axis label $=$ months. 
Table 2. Soil surface conditions during radiometer visits.

\begin{tabular}{cc}
\hline Date of Visit & Plot/Soil Conditions \\
\hline 19-20 October & Unfrozen soil-no snow \\
10-12 November & Frozen soil-no snow \\
9-10 December & Frozen soil-snow \\
11-13 January & Frozen soil-snow \\
12-13 April & Unfrozen soil-no snow \\
\hline
\end{tabular}

In general, the snowpack consisted of low density depth hoar near the bottom of the pack, overlaid with mixed rounded and faceted grains (Figure 3). These depth hoar and mixed rounded/faceted grains are created by kinetic snow metamorphism related to a strong temperature gradient within the snowpack [30]. Above these layers, there was typically a wind slab layer characterized by small rounded grains and high snow density due to strong wind compaction processes [31]. These high density wind slab layers were notably absent from the pasture plot (NW07) because the long grass and emergent vegetation protruding from the snowpack greatly reduced the wind velocity at the snow surface, thereby limiting wind compaction processes. Several melt events in December and January created melt/ice crusts layers near the surface of the snowpack, which were subsequently buried by new snow in February.

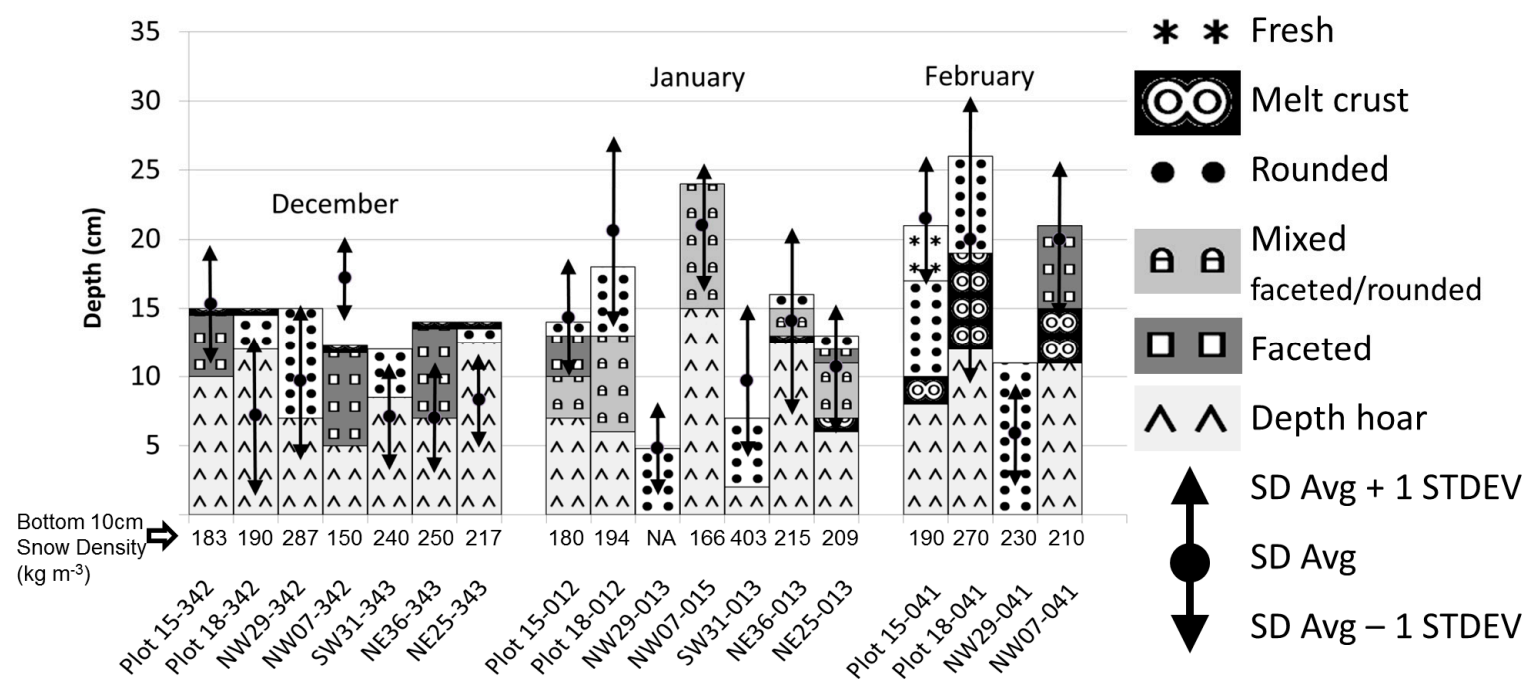

Figure 3. Snow pit measurements during December, January and February illustrating the snow stratigraphy and grain type for each layer. The snow density $\left(\mathrm{kg} \mathrm{m}^{-3}\right)$ of the bottom $10 \mathrm{~cm}$ of the snowpack for each snow pit is provided, along with the average snow depth (SD Avg), \pm 1 standard deviation (STDEV) as measured by with a Magna Probe ${ }^{\mathrm{TM}}$ for the site surrounding the survey location.

The Magna Probe snow depth surveys at each plot highlight both the meter-scale spatial variability of snow depth within each plot (high standard deviation relative to average snow depth), in addition to the different snow accumulation patterns in different fields associated with high and low crop stubble (deep snow vs. shallow snow). For this analysis, Plot NW07 was considered as high stubble, while Plot15 was excluded from the snow depth analysis because the site was not representative of either a high stubble or low stubble crop field. The difference in snow accumulation between high and low stubble fields (average and standard deviation for all plots of a given stubble type) increases as the season progresses, starting with only $2 \mathrm{~cm}$ difference in average snow depth in December, and increasing to $16.8 \mathrm{~cm}$ difference in February (Table 3). The average coefficient-of-variation (CV) of 0.53 is very close to the 0.5 found for prairie snow in [32]. The correlation coefficient $(R)$ between $C V$ and snow depth show a decrease in CV with increasing snow depth $(R=0.63$ and slope $=-0.015)$, meaning the snow depth variance becomes smaller relative to snow depth with increasing accumulation. 
Table 3. Average, standard (STDEV) deviation, coefficient of variation (CV = STDEV/Average), minimum (MIN) and maximum (MAX) snow depths measured at all radiometer plots for high vs. low stubble fields.

\begin{tabular}{ccccccc}
\hline Visits: Stubbles & \# Meas. & Average (cm) & STDEV & CV & MIN (cm) & MAX (cm) \\
\hline December-January-February: high stubble & 1444 & 12.0 & 6.4 & 0.53 & 0.1 & 42.9 \\
December-January-February: Low stubble & 1144 & 8.6 & 5.4 & 0.63 & 0.2 & 33.6 \\
December: high stubble & 1018 & 10.4 & 5.1 & 0.49 & 0.1 & 25.5 \\
January: high stubble & 319 & 13.8 & 6.0 & 0.43 & 2.6 & 33.1 \\
February: high stubble & 107 & 21.9 & 8.6 & 0.39 & 1.7 & 42.9 \\
December: Low stubble & 733 & 8.0 & 4.6 & 0.56 & 0.2 & 23.8 \\
January: Low stubble & 383 & 9.8 & 6.6 & 0.67 & 1.3 & 33.6 \\
February: Low stubble & 102 & 5.1 & 3.1 & 0.61 & 0.6 & 13.9 \\
\hline
\end{tabular}

\subsection{Meter-Scale $T_{B}$ Spatial Variability}

The three parallel adjacent L-Band radiometer measurements ( $2.5 \mathrm{~m}$ apart) conducted at each plot provide the opportunity to evaluate the local variability in observed $T_{B}$ present within each plot location/field type. The standard deviation of the three adjacent L-Band radiometer measurements $\left(\sigma_{\mathrm{TB}}\right)$ was calculated for each plot and visit. Figure 4 shows that the $\sigma_{\mathrm{TB}}$ is generally higher at H-pol (and greater than the precision of the radiometer) and in some cases the $\sigma_{\mathrm{TB}}$ exceeded $5 \mathrm{~K}$ (i.e., at NW07; Figure 4). The local variability is also greater in April because of the variable SM conditions present within the fields soon after snowmelt. The high $\sigma_{\mathrm{TB}}$ at NW07 is likely related to the higher surface roughness (Table 1). At V-pol, the $\sigma_{\mathrm{TB}}$ is generally under $2 \mathrm{~K}$, and even smaller during freeze periods which is close to the precision of the radiometer system.
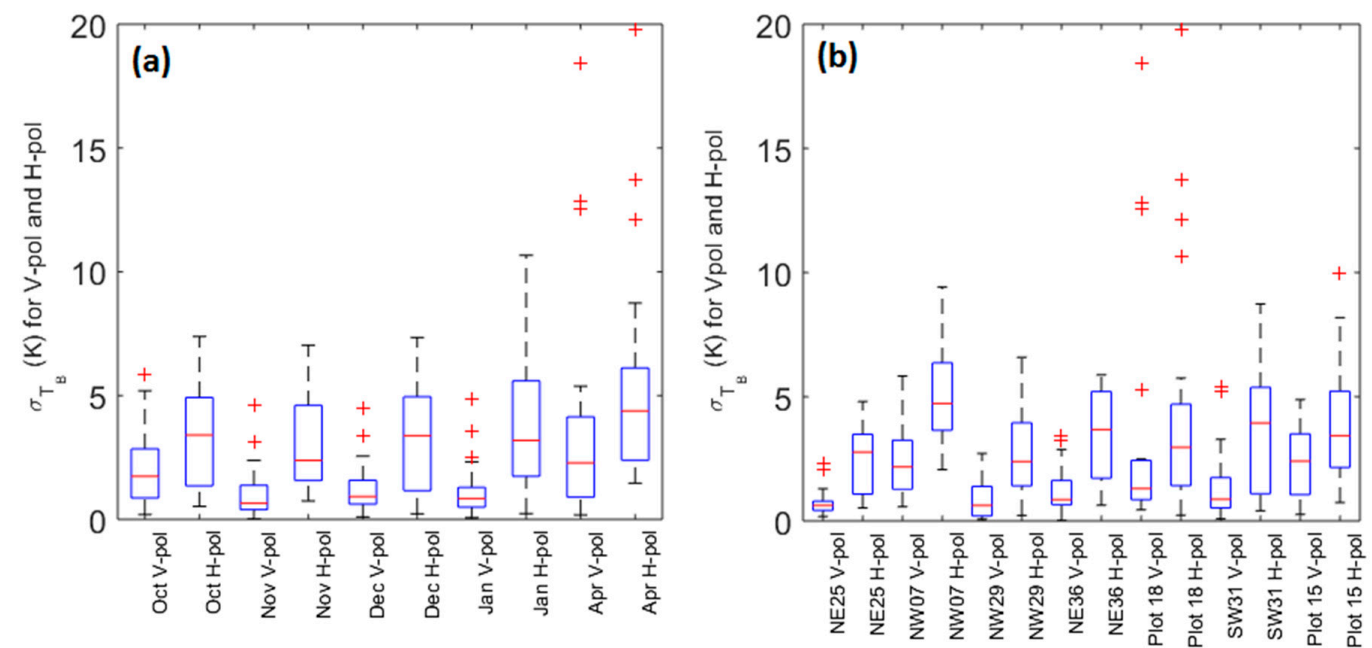

Figure 4. (a) Boxplots (the central red mark is the median, the horizontal blue edges of the box are the 25th and 75th percentiles, the whiskers extend to the most extreme data points not considered outliers, and outliers [value that is more than three scaled median absolute deviations away from the median] are plotted individually) of the standard deviation of the three parallel adjacent L-Band radiometer measurements $\left(\sigma_{\mathrm{TB}}\right)$ at the seven radiometer plots and four incidence angles. (b) Box plot of $\sigma_{\mathrm{TB}}$ for the five visits and four incidence angles.

\section{3. $T_{B}$ Relationships with Soil and Snow In Situ Measurements}

Radiometer $\mathrm{T}_{B}$ measurements (averaged from the three adjacent measurements described in Section 3.2) at the seven different prairie plots were compared to in situ measurements of soil moisture, permittivity, snow density, and surface roughness (Figure 5). For the three visits during frozen conditions, there are negative correlations between $T_{B}$ at $40^{\circ}$ and the permittivity $\left(\varepsilon_{G}\right)$ (Figure $\left.5 b, d, f\right)$. However, the correlation of $\mathrm{T}_{\mathrm{B}}$ with $\varepsilon_{\mathrm{G}}$ is only significant $(p$-value $<0.05)$ during the initial freeze-up in November. The subsequent weakening of the correlation between $T_{B}$ and $\varepsilon_{G}$ in December and 
January can be attributed to the presence of snow on the ground. Schwank et al. [33] presented model results that show the bottom $\approx 10 \mathrm{~cm}$ layer of the snowpack can have an effect on increasing emission on $\mathrm{H}$-pol $\mathrm{T}_{\mathrm{B}}$ as a result of refraction and impedance matching caused by dry snow in contact with the ground. These refraction and impedance matching effects increase as the snow density of the bottom layer increases up to $\approx 400 \mathrm{~kg} \mathrm{~m}^{-3}$ [13]. However, in the present study, the measured snow density of the bottom $10 \mathrm{~cm}$ of snowpack had low correlations with $\mathrm{H}$-pol $\mathrm{T}_{\mathrm{B}}$ at the ground-based radiometer plots (Figure $5 \mathrm{e}-\mathrm{g}$ ). This lack of correlation is likely due to a combination of the plot scale variability in measured $\mathrm{H}$-pol $\mathrm{T}_{\mathrm{B}}$ (Figure 4), and the high local scale spatial variability in snow depths (Table 3), which controls the thickness and snow density of the bottom $10 \mathrm{~cm}$ of the pack. Therefore, the overlying snow still contributed to the weaker correlation of $\varepsilon_{G}$ with $T_{B}$ in December and January compared to November, even though the relationship with measured bottom layer snow density was weak.
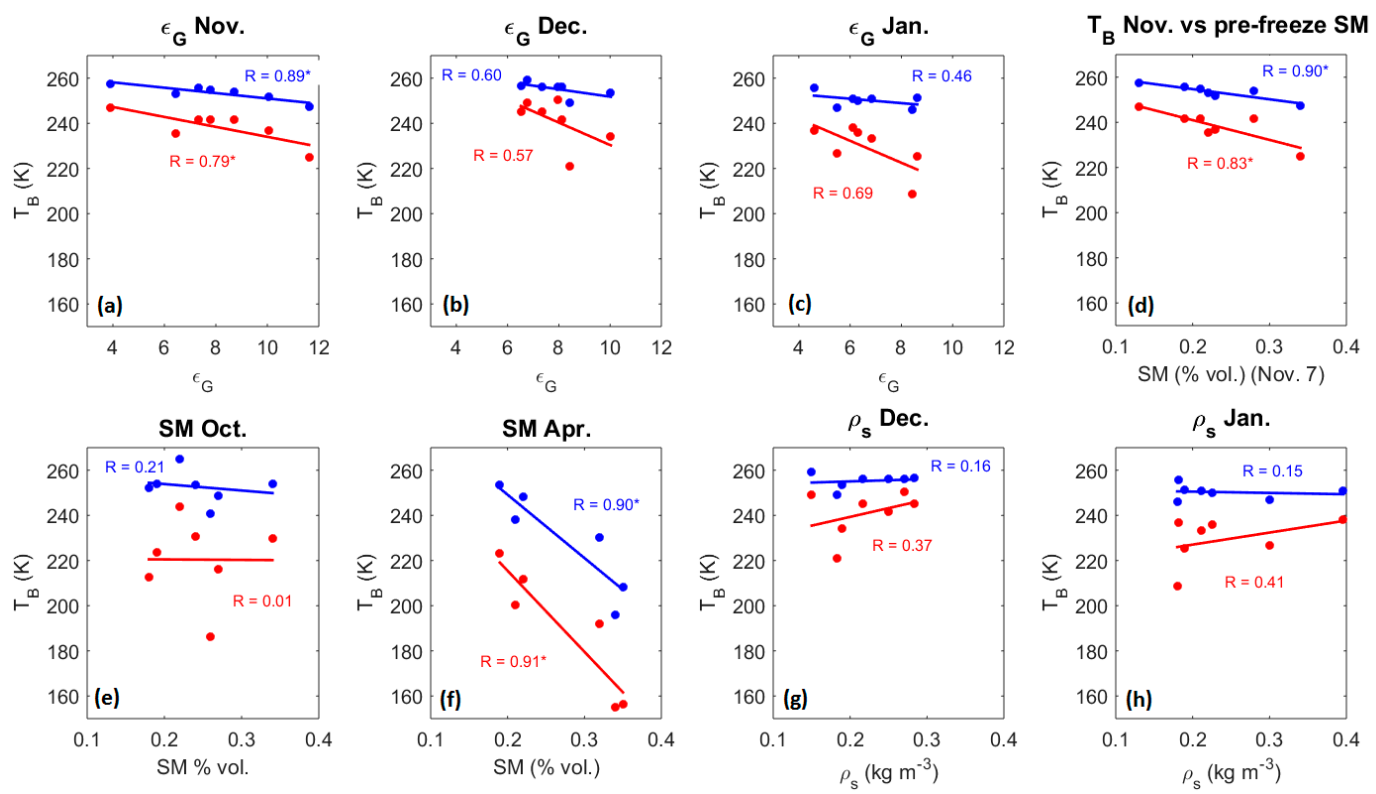

Figure 5. Correlations between surface variables $\left(\mathrm{SM}=\right.$ soil moisture; $\varepsilon_{\mathrm{G}}=$ soil permittivity; $\rho \mathrm{s}=$ snow density) and ground based brightness temperature $\left(\mathrm{T}_{\mathrm{B}}\right)$ at $40^{\circ}$ for different plot visits. ${ }^{*}$ indicates p-value < 0.05. Blue: V-pol and Red: H-pol. (a) ground permittivity vs. $\mathrm{T}_{\mathrm{B}}$ in November; (b) ground permittivity vs. $\mathrm{T}_{\mathrm{B}}$ in December; (c) ground permittivity vs. $\mathrm{T}_{\mathrm{B}}$ in January; (d) $\mathrm{T}_{\mathrm{B}}$ in November (frozen ground) vs. pre-freeze soil moisture on 7 November; (e) Soil moisture vs. $T_{B}$ in October; (f) Soil moisture vs. $\mathrm{T}_{\mathrm{B}}$ in April; (g) Snow density vs. $\mathrm{T}_{\mathrm{B}}$ in December; (h) Snow density and $\mathrm{T}_{\mathrm{B}}$ in January.

In April, the $\mathrm{T}_{\mathrm{B}}$ is highly correlated with SM (Figure 5h). However, the correlation is weak in October (Figure 5a), possibly due to the drier soil conditions. The correlation between pre-freeze SM conditions measured on 7 November and the $T_{B}$ of frozen ground measured from 10th November to 12th are strong (Figure 5d). Considering the pre-frozen soil moisture measurements as a proxy for soil ice fraction content over the course of three days, this suggests that the amount of ice in the soil greatly influences the magnitude of frozen ground $T_{B}$. Figure 6 shows that the surface roughness also has a positive correlation with $\mathrm{T}_{\mathrm{B}}$. There is a moderate strength in the correlations, but the small sample size means the correlation is not statistically significant ( $p$-value $>0.05$ ) However, the consistency of the positive correlations indicates that the surface roughness contributes to the observed variability in $\mathrm{T}_{\mathrm{B}}$ at both polarizations. The correlation coefficients with soil roughness decrease in December and January mostly at H-pol, related to the effect of snow which interferes with the frozen soil emission. The low correlation values in April at both polarizations are linked to the fact that the SM signal overrides the surface roughness effect. 

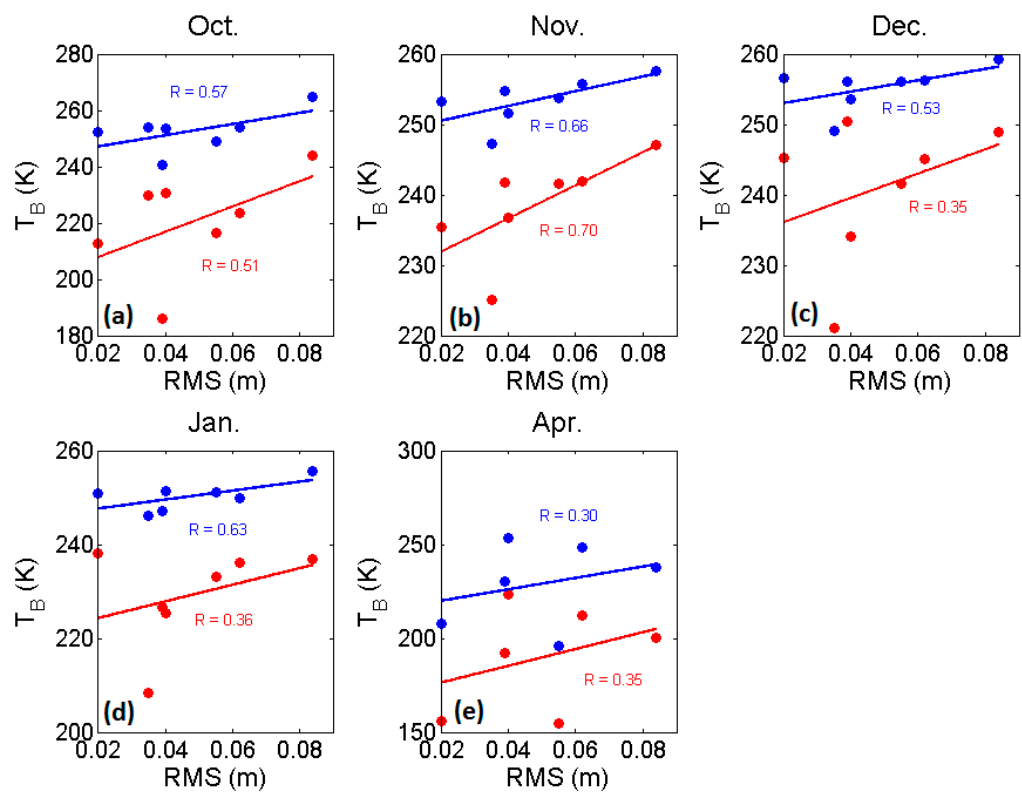

Figure 6. Correlations between soil surface roughness parameter root mean square height (RMS, $\mathrm{m}$ ) and ground based $\mathrm{T}_{\mathrm{B}}$ at $40^{\circ}$ for different visits. All $p$-values $>0.05$. Blue $=\mathrm{V}$-pol and Red $=\mathrm{H}$-pol. (a) RMS vs. $\mathrm{T}_{\mathrm{B}}$ in October; (b) RMS vs. $\mathrm{T}_{\mathrm{B}}$ in November; (c) RMS vs. $\mathrm{T}_{\mathrm{B}}$ in December; (d) RMS vs. $\mathrm{T}_{\mathrm{B}}$ in January; (e) RMS vs. $\mathrm{T}_{\mathrm{B}}$ in April.

\subsection{SMOS Sub-Pixel Heterogeneity}

The agreement between the averaged ground-based measurements and SMOS observations are generally good with the observed SMOS $\mathrm{T}_{\mathrm{B}}$ typically falling within the standard deviation of ground-based radiometer $\mathrm{T}_{\mathrm{B}}$ (Figure 7). When the $60^{\circ}$ incidence angles are excluded, the root mean square difference between (RMSD) $\mathrm{T}_{\mathrm{B}-\mathrm{SMOS}}$ and $T_{B \text {-Rad }}$ is $8.4 \mathrm{~K}$. Both datasets show a clear difference in $\mathrm{T}_{B}$ at $\mathrm{H}$-pol in October (unfrozen soil), relative to November (frozen soil with no snow). This H-pol increase is dependent on incidence angle, with larger differences in unfrozen compared to frozen $T_{B}$ observed at larger incidence angles [11]. The V-pol is less sensitive to the transition from unfrozen to frozen soil conditions, with only a small increase observed in V-pol SMOS $\mathrm{T}_{\mathrm{B}}$ at $30^{\circ}$ and $40^{\circ}$. The winter SMOS observations show relatively stable $T_{B}$ throughout the frozen season at all angles, with a few exceptions during which strong $\mathrm{T}_{\mathrm{B}}$ fluctuations are related to freeze/thaw events (see Figure 2 for periods when $\mathrm{T}_{\text {air }}<0{ }^{\circ} \mathrm{C}$ ). The radiometer $\mathrm{T}_{\mathrm{B}}$ at $\mathrm{V}$-pol are also stable throughout the winter, however some variability at $\mathrm{H}-\mathrm{pol}$ is observed. There is a reduction in radiometer observed $\mathrm{H}-\mathrm{pol} \mathrm{T}_{\mathrm{B}}$ in January compared to December and November, and the standard deviation increases as the season progresses and incidence angles increase. In March, a strong decrease in SMOS $\mathrm{T}_{\mathrm{B}}$ is related to the onset of snow melt and the presence of liquid water within and on the snow pack or at the soil surface. In April, as the soil dries down, there is again good agreement between the average ground-based radiometer and SMOS $T_{B}$. The ground-based radiometer observed a much higher range of $T_{B}$ in April, which is likely attributed to plot-scale variability in snow melt and dry down of the soils across the SMOS pixel. The largest discrepancies between SMOS and the ground-based radiometer observations are seen at V-pol for an incidence angle of $60^{\circ}$. The $T_{B \text {-Rad-W }}$ are 8.5 to $22.9 \mathrm{~K}$ bellow the satellite observations (Table 4). At incidence angles, larger than $60^{\circ}$, Lemmetyinen et al. [12] showed that V-pol $\mathrm{T}_{\mathrm{B}}$ undergoes a strong decrease in magnitude. In our study, the radiometer system has a larger beamwidth $\left(30^{\circ}\right)$. The radiometer is effectively viewing the surface with an incidence angle in the far range of up to $75^{\circ}$, which may be exaggerating the influence of high incidence angles on reducing the magnitude of $\mathrm{V}-$ pol $\mathrm{T}_{\mathrm{B}}$.

The standard deviation of $\mathrm{T}_{\mathrm{B}}$ between the seven radiometer plots is much larger when the soil surface is thawed in October and April. In October, the standard deviation is larger at H-pol (between 
15 and $25 \mathrm{~K}$ ) than V-pol (between 5.9 and $8.1 \mathrm{~K}$ ), while both are high in April. The high $\mathrm{T}_{\mathrm{B}}$ standard deviation in V-pol in April is likely related to the spatial variability of SM conditions related to the snowmelt. When the soil is frozen (November, December, and January) the spatial variability is lower, but remains significant (higher than radiometer precision) at $\mathrm{H}$-pol mostly for higher incidence angle. The standard deviations are between $2.7 \mathrm{~K}$ and $16.4 \mathrm{~K}$ at $\mathrm{H}$-pol and $0.8 \mathrm{~K}$ and $3.1 \mathrm{~K}$ at V-pol.

In comparison to $T_{B-R a d}$, when $60^{\circ}$ is excluded, the RMSD between $T_{B-S M O S}$ and $T_{B-R a d-W}$ is $12.4 \mathrm{~K}$ (8.4 K with $\left.T_{B-R a d}\right)$. This suggests that the land cover type proportional weighting does not improve the results. The weighted approach generally has a higher bias when compared to $\mathrm{T}_{\mathrm{B}-\mathrm{SMOS}}$. It suggests that the lower values at Plot 15 compensate for the fact that wetlands and water bodies, which have lower $T_{B}$ values, are not considered in the weighting approach. In terms of the difference between $\sigma_{\text {Rad }}$ and $\sigma_{\text {Rad-W, }}$, the average in winter and summer are similar at around $3 \mathrm{~K}$. The lowest values of $\sigma_{\text {Rad-W }}$ show that part of the spatial variability is related to the $T_{B}$ measured at Plot15 (considered as not representative because of the low coverage of this type of land cover) and NW07 (pasture). However, despite the effect of plot NW07 and Plot15 on spatial variability of $\mathrm{T}_{\mathrm{B}}$, the spatial variability across the five visited crop plots remains high.

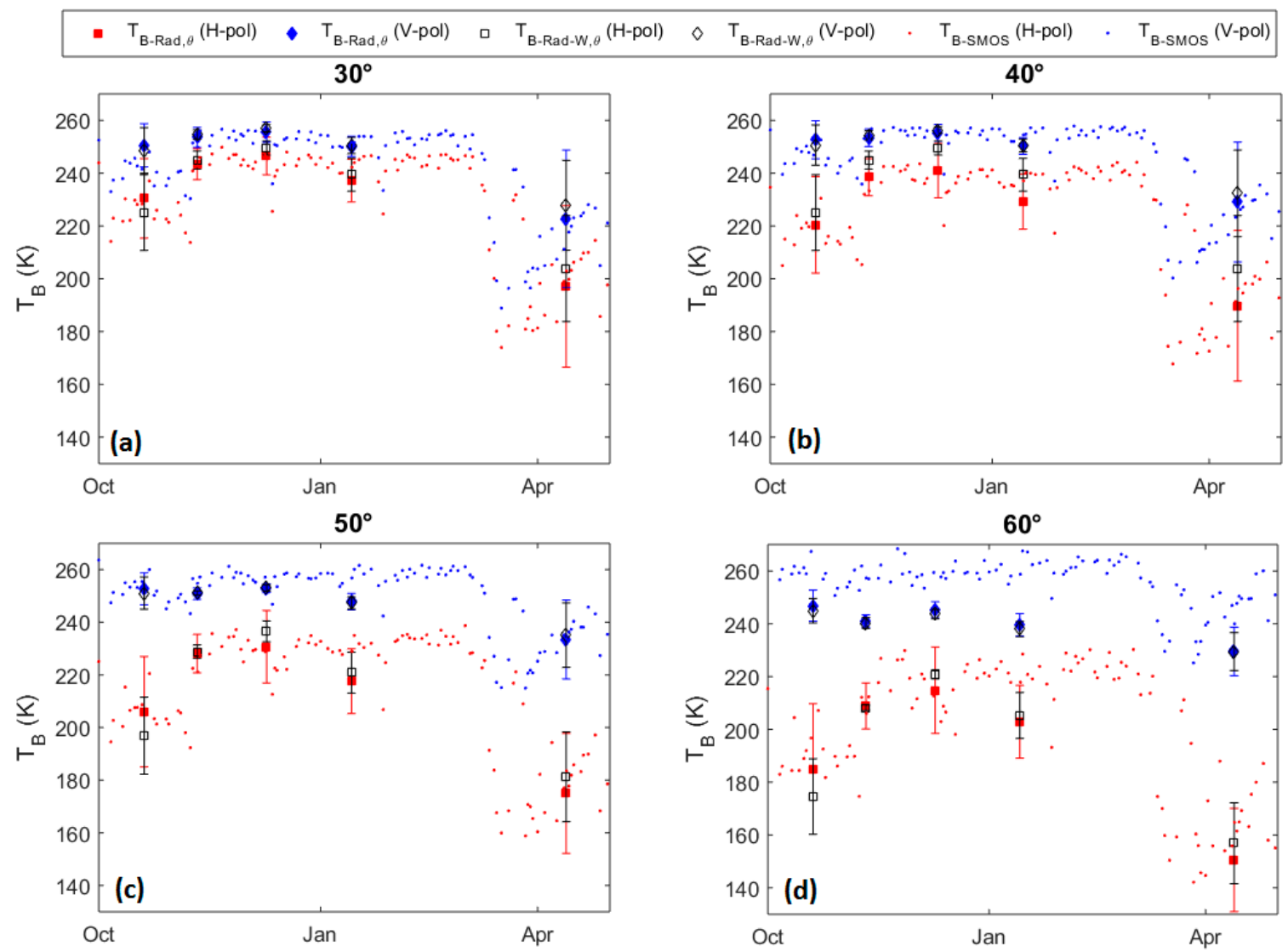

Figure 7. KSMN visits mean ground-based radiometer $\mathrm{T}_{\mathrm{B}}$ and standard deviation over the seven plots at H-pol (red square) and V-pol (blue diamond) at four incidence angles (a) $30^{\circ}$, (b) $40^{\circ}$, (c) $50^{\circ}$ and (d) $60^{\circ}$. The dots represent the angularly smoothed SMOS $\mathrm{T}_{\mathrm{B}}$ (ascending and descending passes). Red square and blue diamonds are the arithmetic average $\mathrm{T}_{\mathrm{B}}$ of all seven field plots (Equation (1)) and hollowed black square and diamond are land cover-weighted average $\mathrm{T}_{\mathrm{B}}$ (Equation (2)). 
Table 4. Differences between $T_{B-S M O S}$ and $T_{B-R a d} \& T_{B-R a d-W}$ (in $\mathrm{K}$ ) as well as differences between standard deviation of ground-based radiometer observations $(\sigma)$.

\begin{tabular}{|c|c|c|c|c|c|c|c|c|c|}
\hline \multirow{2}{*}{ Months } & \multirow{2}{*}{ Parameters } & \multicolumn{2}{|c|}{$30^{\circ}$} & \multicolumn{2}{|c|}{$40^{\circ}$} & \multicolumn{2}{|c|}{$50^{\circ}$} & \multicolumn{2}{|c|}{$60^{\circ}$} \\
\hline & & $\mathbf{H}$ & V & $\mathbf{H}$ & $\mathbf{V}$ & $\mathbf{H}$ & $\mathbf{V}$ & $\mathbf{H}$ & $\mathbf{V}$ \\
\hline \multirow{3}{*}{ October } & $T_{B-S M O S}-T_{B-R a d}$ & 5.3 & 1.9 & -4.7 & 2.1 & 9.1 & 1.7 & 10.4 & 1.9 \\
\hline & $T_{B-S M O S}-T_{B-R a d-W}$ & 3.2 & -7.1 & -5.9 & -3.8 & 11.8 & 4.5 & 22.1 & 22.5 \\
\hline & $\sigma_{\text {Rad }}{ }^{-} \sigma_{\text {Rad-W }}$ & 0.7 & -0.4 & 4.9 & -0.4 & 6.4 & 0.0 & 10.4 & 1.3 \\
\hline \multirow{3}{*}{ November } & $T_{B-S M O S}-T_{B-R a d}$ & -1.6 & -1.1 & -6.5 & -0.9 & -0.7 & -0.3 & 0.7 & 0.6 \\
\hline & $T_{B-S M O S}-T_{B-R a d-W}$ & -2.3 & -4.7 & -11.7 & -2.0 & -7.7 & 3.7 & -2.1 & 17.0 \\
\hline & $\sigma_{\text {Rad }}{ }^{-} \sigma_{\text {Rad-W }}$ & 2.5 & 2.1 & 3.6 & 1.5 & 4.7 & 1.4 & 7.7 & 0.3 \\
\hline \multirow{3}{*}{ December } & $T_{B-S M O S}-T_{B-R a d}$ & -3.0 & -1.5 & -8.6 & -1.0 & -5.8 & -0.1 & -6.0 & 1.6 \\
\hline & $T_{B-S M O S}-T_{B-R a d-W}$ & -2.9 & -3.3 & -9.4 & -1.1 & -7.7 & 4.1 & -8.1 & 15.7 \\
\hline & $\sigma_{\text {Rad }}-\sigma_{\text {Rad-W }}$ & 4.5 & 2.5 & 7.7 & 1.9 & 9.8 & 0.4 & 14.7 & 1.3 \\
\hline \multirow{3}{*}{ January } & $T_{B-S M O S}-T_{B-R a d}$ & 2.2 & 0.4 & 10.2 & 0.2 & 3.2 & -0.5 & 2.4 & -1.6 \\
\hline & $T_{B-S M O S}-T_{B-R a d-W}$ & 2.9 & 1.3 & -2.3 & 4.0 & 8.2 & 9.5 & 12.6 & 20.7 \\
\hline & $\sigma_{R_{\text {Rad }}} \sigma_{\text {Rad-W }}$ & 1.9 & 0.7 & 4.2 & 0.6 & 4.5 & 0.8 & 5.1 & 1.3 \\
\hline \multirow{3}{*}{ April } & $T_{B-S M O S}-T_{B-R a d}$ & 6.8 & 5.1 & 14.1 & 3.3 & 6.4 & 1.7 & 6.4 & 0.0 \\
\hline & $T_{B-S M O S}-T_{B-R a d-W}$ & -0.9 & -6.9 & -7.6 & -5.1 & 2.2 & -1.5 & 7.9 & 10.5 \\
\hline & $\sigma_{R a d}-\sigma_{R a d-W}$ & 10.5 & 9.0 & 8.4 & 6.3 & 5.7 & 2.8 & 4.2 & 2.0 \\
\hline
\end{tabular}

\section{Discussion}

For each plot and each date, three adjacent radiometer measurements $(2.5 \mathrm{~m})$ were conducted to gain a sense of the local variability in observed brightness temperatures present within each plot location. In some cases, the standard deviations of these measurements were over $5 \mathrm{~K}$ at $\mathrm{H}$-pol both for both frozen and thawed conditions. These higher values are related to the increased sensitivity of $\mathrm{H}$-pol to surface roughness [27]. These results highlight the local-scale $\mathrm{H}$-pol $\mathrm{T}_{\mathrm{B}}$ variability found within the prairie environment and the importance to make adjacent measurements to take account of variations in parameters such as surface roughness and SM.

As expected, the spatial variability of ground-based $\mathrm{T}_{\mathrm{B}}$ across the KSNM network in April was well correlated with SM and, to lesser degree, with surface roughness. More surprising was the correlation of $\mathrm{T}_{\mathrm{B}}$ during frozen conditions with $\varepsilon_{\mathrm{G}}$. These correlations indicate that the variable characteristics of frozen soils in a prairie environment, including the ice fraction of the soil, can have an impact on $T_{B}$ and there may be further information in this signal beyond the binary freeze versus thaw signal that nearly all algorithms produce. These results should be taken into consideration with respect to satellite-based L-Band observations under frozen conditions. For instance, in the SMOS SM algorithm, the frozen soil permittivity is generally considered as a constant [29]. Instead, retrieval approaches that include frozen ground permittivity should be considered for implementation in such algorithms [12]. This increases the importance of frozen ground permittivity models (e.g., [34,35]). As demonstrated in previous studies $[12,13,33,36]$, snow has a non-negligible effect on the $\mathrm{T}_{\mathrm{B}}$ at $\mathrm{H}$-pol. However, in this study, the correlation of $\mathrm{T}_{\mathrm{B}}$ with measured bottom layer snow density was low, but we infer the importance of snow through weaker correlation of $T_{B}$ with $\varepsilon_{G}$ and with roughness during the dry snow cover period. Furthermore, ice lenses formed during the ephemeral F/T events in winter can lead to important dielectric discontinuities in the snowpack, causing also possible coherence effects that can have a notable impact on $\mathrm{T}_{\mathrm{B}}$ [37-39]. Further evaluation using multi-layer snow radiative transfer models $[40,41]$ need to better quantify and understand these variations.

The measurements presented in this study show that even if the Canadian Prairies are considered a relatively homogenous landscape, the spatial variability of $\mathrm{T}_{B}$ at $\mathrm{H}-\mathrm{pol}$ is important. However, the spatial variability is significantly lower when the surface is frozen (around $10 \mathrm{~K}$ in frozen conditions vs. $20 \mathrm{~K}$ in thawed conditions). This strong spatial variability shows the limitation of using point ground-based measurements to validate/calibrate satellite based $\mathrm{F} / \mathrm{T}$ and SM products. It was also shown that the average $T_{B}$ of the seven plots are well correlated with the SMOS $T_{B}$ and the strong $F / T$ signal (increase of $T_{B}$ when soil freezes and decrease in $T_{B}$ when soil thaws) is also well represented. Thus, averaged L-Band ground-based measurements can represent a large footprint satellite-based $T_{B}$ if sites are reasonably selected to account for the spatial variability. However, it should be noted that there are differences in measurement characteristics between SMOS and ground-based radiometers. 
First, the SMOS observations are done in the morning (ascending pass) or in the evening (descending pass). With ground-based radiometer, the measurements were acquired during the day from $6 \mathrm{am}$ to $5 \mathrm{pm}$. Hence there could be some surface changes (temperature, moisture, snow) between SMOS and ground-based acquisition. However, it was shown that in the prairies, when the soil is frozen, the $T_{B}$ is relatively stable in time because the soil temperature is stable due to the snow insulation [13]. Nevertheless, it should be considered that in general, difference in $\mathrm{T}_{B}$ could be related to the acquisition time differences. Secondly, SMOS provides $T_{B}$ at the top of the atmosphere, that is not measured by ground-based radiometer. However, De Lannoy et al. [42] showed that the atmospheric contribution is limited to less than $2 \mathrm{~K}$ in $\mathrm{H}$-pol and less than $1 \mathrm{~K}$ in V-pol. In this study, it was shown that the L-Band emissivity of the surface can vary significantly even over bare soil surfaces. Hence, ground-based radiometer campaigns should make sure that all dominant land cover classes are well represented. Ideally, multiple measurements within a given land cover should also be taken to make sure that measurements are not skewed by local-scale $T_{B}$ spatial variability. Furthermore, this study focused on the vegetation-free season, but it is known that the crop growth cycle had an important impact on the L-Band signal in summer [43] during which even greater sub-pixel variability is expected.

\section{Conclusions}

Sub-pixel heterogeneity is a well-known difficulty for passive microwave satellite-borne land product calibration and validation. In this study, an L-Band ground-based radiometer campaign was conducted across a densely instrumented Canadian Prairies site during winter 2014-2015 to measure the spatial variability of surface emission during frozen and unfrozen soil conditions. Radiometer measurements were acquired five times during the freeze/thaw season (October, November, December, January, April) distributed across a single SMOS pixel.

This study provides the first measurements of the spatial variability in L-Band emission using a ground-based radiometer for comparison with satellite observations during frozen and unfrozen conditions. We show that the spatial variability of $\mathrm{T}_{\mathrm{B}}$ at $\mathrm{H}-$ pol within a SMOS subpixel is important in both frozen and unfrozen conditions, with standard deviation up to $25 \mathrm{~K}$. However, we showed that compared to satellite measurements, the average $\mathrm{T}_{\mathrm{B}}$ of the seven plots were well correlated with the SMOS $\mathrm{T}_{\mathrm{B}}$ with a root mean square difference of $8.1 \mathrm{~K}$ and consistent representation of the strong $\mathrm{F} / \mathrm{T}$ signal. Hence, ground-based measurements can be representative of satellite-based observations, if multiple spatially distributed measurements are taken to take into account the spatial variability of surface emission. The spatial variability is mostly related to the measured soil permittivity, which is related to SM in unfrozen conditions ( $R$ of 0.90 and 0.91 between $T_{B}$ and $\varepsilon_{G}$ in April for V-pol and H-pol respectively) and to ice fraction in frozen conditions ( $R$ of 0.89 and 0.79 between $T_{B}$ and $\varepsilon_{G}$ in November for V-pol and H-pol respectively). This shows that the ice fraction of the soil can have an impact on $T_{B}$ and should be taken into consideration with respect to satellite-based L-Band observations under frozen conditions. The study highlights the limitations in using single point observations (either of soil state characteristics or emission) in algorithm development studies and satellite validation, as sub-pixel variability has an important impact. However, it should be noted that the study is limited to the prairie environment and studies in other landscapes would be important to understand the spatial variability of L-Band emission in various ecosystems.

Acknowledgments: The authors would like to thank the Canadian Space Agency (CSA), the Natural Sciences and Engineering Research Council of Canada (NSERC) and European Space Agency (ESA) for their financial support. We would like to thank Lauren Arnold, Arvids Silis, Craig Smith (Environment and Climate Change Canada), Matthew Williamson (University of Guelph) and Bruce Johnson (University of Saskatchewan) for their help with field measurements.

Author Contributions: Alexandre Roy, Peter Toose, Chris Derksen, Aaron Berg, Juha Lemmetyinen, Alain Royer and Tracy Rowlandson designed the study. Alexandre Roy, Peter Toose, Chris Derksen, Juha Lemmetyinen, Aaron Berg, Tracy Rowlandson, Warren Helgason and Erica Tetlock collected the data. Alexandre Roy, Peter Toose and Erica Tetlock processed the data. All authors contributed in editing the manuscript.

Conflicts of Interest: The authors declare no conflict of interest. 


\section{References}

1. Black, T.A.; Chen, W.; Barr, A.; Arain, A.; Chen, Z.; Nesic, Z.; Hogg, E.; Neumann, H.; Yang, P. Increased carbon sequestration by a boreal deciduous forest in years with a warm spring. Geophys. Res. Lett. 2000, 27, 1271-1274. [CrossRef]

2. Wagner-Riddle, C.; Congreves, K.A.; Abalos, D.; Tenuta, M.; Berg, A.A.; Brown, S.E.; Thomas, J.; Gao, X. Global importance of soil freeze-thaw induced emissions of nitrous oxide from croplands. Nat. Geosci. 2017, 10, 279-283. [CrossRef]

3. Kim, Y.; Kimball, J.S.; Zhang, K.; McDonald, K.C. Satellite detection of increasing Northern Hemisphere non-frozen seasons from 1979 to 2008: Implications for regional vegetation growth. Remote Sens. Environ. 2012, 121, 472-487. [CrossRef]

4. Gouttevin, I.; Menegoz, M.; Domine, F.; Krinner, G.; Ciais, P.; Tarnocai, C.; Boike, J. How the insulating properties of snow affect soil carbon distribution in the continental pan-arctic area. J. Geophys. Res. 2012, 117, G02020. [CrossRef]

5. Gray, D.M.; Landine, P.G.; Granger, R.J. Simulating infiltration into frozen prairie soils in stream flow models. Can. J. Earth Sci. 1985, 22, 464-474.

6. Cade-Menun, B.J.; Bell, G.; Baker-Ismail, S.; Fouli, Y.; Hodder, K.; McMartin, D.W.; Perez-Valdivia, C.; Wu, K. Nutrient loss from Saskatchewan cropland and pasture in spring snowmelt runoff. Can. J. Soil Sci. 2013, 93, 445-458. [CrossRef]

7. Mätzler, C.; Ellison, W.; Thomas, B.; Sihvola, A.; Schwank, M. Dielectric properties of natural media. In Thermal Microwave Radiation: Applications for Remote Sensing; Mätzler, C., Ed.; The Institution of Engineering and Technology: London, UK, 2006; pp. 427-539.

8. Xu, X.; Derksen, C.; Yueh, S.; Dunbar, R.S.; Colliander, A. Freeze/thaw detection and validation using Aquarius L-band backscattering data. IEEE J. Sel. Top. Appl. Earth Obs. Remote Sens. 2016, 9, 1370-1381. [CrossRef]

9. Rautiainen, K.; Parkkinen, T.; Lemmetyinen, J.; Schwank, M.; Wiesmann, A.; Ikonen, J.; Derksen, C.; Davydov, S.; Davydova, A.; Boike, J.; et al. SMOS prototype algorithm for detecting autumn soil freezing. Remote Sens. Environ. 2016, 180, 346-360. [CrossRef]

10. Derksen, C.; Xu, X.; Dunbar, R.S.; Colliander, A.; Kim, Y.; Kimball, J.S.; Black, T.A.; Euskirchen, E.; Langlois, A.; Loranty, M.M.; et al. Retrieving landscape freeze/thaw state from soil moisture active passive (SMAP) radar and radiometer measurements. Remote Sens. Environ. 2017, 194, 48-62. [CrossRef]

11. Roy, A.; Royer, A.; Derksen, C.; Brucker, L.; Langlois, A.; Mialon, A.; Kerr, Y. Evaluation of spaceborne L-band radiometer measurements for terrestrial freeze/thaw retrievals in Canada. IEEE J. Sel. Top. Appl. Earth Obs. Remote Sens. 2015, 99, 1404-1939. [CrossRef]

12. Lemmetyinen, J.; Schwank, M.; Rautiainen, K.; Parkkinen, T.; Mätzler, C.; Wiesmann, A.; Wegmüller, U.; Derksen, C.; Toose, P.; Roy, A.; et al. Snow density and ground permittivity retrieved from L-band radiometry: Application to experimental data. Remote Sens. Environ. 2016, 180, 377-391. [CrossRef]

13. Roy, A.; Toose, P.; Williamson, M.; Rowlandson, T.; Derksen, C.; Royer, A.; Berg, A.A.; Lemmetyinen, J.; Arnold, L. Response of L-band brightness temperatures to freeze/thaw and snow dynamics in a prairie environment from ground-based radiometer measurements. Remote Sens. Environ. 2017, 191, 67-80. [CrossRef]

14. Rautiainen, K.; Lemmetyinen, J.; Pulliainen, J.; Vehviläinen, J.; Drusch, M.; Kontu, A.; Seppänen, J. L-band radiometer observations of soil processes at boreal and sub-arctic environments. IEEE Trans. Geosci. Remote Sens. 2012, 50, 1483-1497. [CrossRef]

15. Wigneron, J.-P.; Jackson, T.J.; O’Neill, P.; De Lannoy, G.; de Rosnay, P.; Walker, J.P.; Ferrazzoli, P.; Mironov, V.; Bircher, S.; Grant, J.P.; et al. Modelling the passive microwave signature from land surfaces: A review of recent results and application to the L-band SMOS and SMAP soil moisture retrieval algorithms. Remote Sens. Environ. 2017, 192, 238-262. [CrossRef]

16. Roy, S.K.; Rowlandson, T.L.; Berg, A.A.; Champagne, C.; Adams, J.R. Impact of sub-pixel heterogeneity on modelled brightness temperature for an agricultural region. Int. J. Appl. Earth Obs. Geoinf. 2016, 45, $212-220$. [CrossRef] 
17. Lemmetyinen, J.; Derksen, C.; Toose, P.; Prokch, M.; Pulliainen, J.; Kontu, A.; Rautiainen, K.; Seppänen, J.; Hallikainen, M. Simulating seasonal and spatially varying snow cover brightness temperature using HUT snow emission model and retrieval of a microwave effective grain size. Remote Sens. Environ. 2015, 156, 71-95. [CrossRef]

18. Larue, F.; Royer, A.; De Sève, D.; Langlois, A.; Roy, A.; Brucker, L. Validation of GlobSnow-2 snow water equivalent over eastern Canada. Remote Sens. Environ. 2017, 194, 264-277. [CrossRef]

19. Rowlandson, T.; Impera, S.; Belanger, J.; Berg, A.A.; Toth, B.; Magagi, M. Use of in situ soil moisture network for estimating regional-scale soil moisture during high soil moisture conditions. Can. Water Resour. J. 2015, 40, 343-351. [CrossRef]

20. Burns, T.T.; Berg, A.A.; Cockburn, J.; Tetlock, E. Regional scale spatial and temporal variability of soil moisture in a prairie region. Hydrol. Process. 2016, 30, 3639-3649. [CrossRef]

21. Burns, T.T.; Adams, J.R.; Berg, A.A. Laboratory calibration procedures of the hydra probe soil moisture sensor: Infiltration wet-up vs. dry-down. Vadose Zone J. 2014, 13. [CrossRef]

22. Toose, P.; Roy, A.; Solheim, F.; Derksen, C.; Royer, A.; Walker, A. Radio frequency interference mitigating hyperspectral L-band radiometer. Geosci. Instrum. Methods Data Syst. 2016, 6, 39-51. [CrossRef]

23. Pellarin, T.; Mialon, A.; Biron, R.; Coulaud, C.; Gibon, F.; Ferr, Y.; Lafaysse, M.; Mercier, B.; Morin, S.; Redor, I.; et al. Three years of L-band brightness temperature measurements in a mountainous area: Topography, vegetation and snowmelt issues. Remote Sens. Environ. 2016, 180, 85-98. [CrossRef]

24. Agriculture and Agri-Food Canada. AAFC Crop Inventory. Available online: http://open.canada.ca (accessed on 12 March 2015).

25. El Titi, A. Effects of tillage on invertebrates in soil ecosystems. In Soil Tillage in Agroecosystems; El Titi, A., Ed.; CRC Press: Boca Raton, FL, USA, 2003; pp. 261-296.

26. Nicholaichuk, W.; Gray, D.M.; Steppuhn, H.; Dyck, F.B. Snow management practices for trapping snow in a Prairie environment. In Proceedings of the Snow Management for Agriculture, Saskatoon, SK, Canada, 9-11 July 1985; pp. 477-499.

27. Wegmüller, U.; Mätzler, C. Rough bare soil reflectivity model. IEEE Trans. Geosci. Remote Sens. 1999, 37, 1391-1395. [CrossRef]

28. Chabot, M. Characterizing Agricultural Surface Roughness Using a Terrestrial Laser Scanner: Implications for Soil Moisture Retrieval from Remote Sensing Products. Master's Thesis, University of Guelph, Guelph, ON, Canada, 2016.

29. Kerr, Y.H.; Waldteufel, P.; Wigneron, J.P.; Delwart, S.; Cabot, F.O.; Boutin, J.; Escorihuela, M.J.; Font, J.; Reul, N.; Gruhier, C.; et al. The SMOS mission: New tool for monitoring key elements of the global water cycle. IEEE Proc. 2010, 98, 666-687. [CrossRef]

30. Colbeck, S. Theory of metamorphism of dry snow. J. Geophys. Res. 1983, 88, 5475-5482. [CrossRef]

31. Li, L.; Pomeroy, J. Estimates of threshold wind speeds for snow transport using meteorological data. J. Appl. Meteorol. 1997, 36, 205-213. [CrossRef]

32. Liston, G.E. Representing subgrid snow cover heterogeneities in regional and global models. Am. Meteorol. Soc. 2004, 17, 1381-1397. [CrossRef]

33. Schwank, M.; Mätzler, C.; Wiesmann, A.; Wegmüller, U.; Pulliainen, J.; Lemmetyinen, J.; Drusch, M. Snow density and ground permittivity retrieved from L-band radiometry: A synthetic analysis. IEEE J. Sel. Top. Appl. Earth Obs. Remote Sens. 2015, 8, 3833-3845. [CrossRef]

34. Mironov, V.L.; De Roo, R.D.; Savin, I.V. Temperature-dependable microwave dielectric model for an Arctic soil. IEEE Trans. Geosci. Remote Sens. 2010, 48, 2544-2556. [CrossRef]

35. Zhang, L.; Shi, J.; Zhang, Z.; Zhao, K. The estimation of dielectric constant of frozen soil-water mixture at microwave bands. In Proceedings of the International Conference on Geoscience and Remote Sensing Symposium, Toulouse, France, 21-25 July 2003; Volume 4, pp. 2903-2905.

36. Schwank, M.; Rautiainen, K.; Mätzler, C.; Stähli, M.; Lemmetyinen, J.; Pulliainen, J.; Vehviläinen, J.; Kontu, A.; Ikonen, J.; Bauduin-Ménard, C.; et al. Model for microwave emission of a snow-covered ground with focus on L-Band. Remote Sens. Environ. 2014, 154, 180-191. [CrossRef]

37. Schwank, M.; Stähli, M.; Wydler, H.; Leuenberger, J.; Mätzler, C.; Flühler, H. Microwave L-band emission of freezing soil. IEEE Trans. Geosci. Remote Sens. 2014, 42, 1252-1261. [CrossRef] 
38. Rees, A.; Lemmetyinen, J.; Derksen, C.; Pulliainen, J.; English, M. Observed and modelled effects of ice lens formation on passive microwave brightness temperatures over snow covered tundra. Remote Sens. Environ. 2010, 114, 116-126. [CrossRef]

39. Naderpour, R.; Schwank, M.; Mätzler, C.; Lemmetyinen, J.; Steffen, K. Snow density and ground permittivity retrieved from L-band radiometry: A retrieval sensitivity study. IEEE J. Sel. Top. Appl. Earth Obs. Remote Sens. 2017. [CrossRef]

40. Huang, S.; Tsang, L. Electromagnetic scattering of randomly rough soil surfaces based on numerical solutions of Maxwell equations in 3 dimensional simulations using a hybrid UV/PBTG/SMCG method. IEEE Trans. Geosci. Remote Sens. 2012, 50, 4025-4035. [CrossRef]

41. Leduc-Leballeur, M.; Picard, G.; Milaon, A.; Arnaud, L.; Lefebvre, E.; Possenti, P.; Kerr, Y. Modeling L-band brightness temperature at dome $\mathrm{C}$ in Antarctica and comparison with SMOS observations. IEEE Trans. Geosci. Remote Sens. 2015, 53, 4022-4032. [CrossRef]

42. De Lannoy, G.J.M.; Reichle, R.H.; Peng, J.; Kerr, Y.; Castro, R.; Kim, E.J.; Liu, Q. Converting between SMOS and SMAP Level-1 brightness temperature observations over non-frozen land. IEEE Geosci. Remote Sens. Lett. 2015, 12, 1908-1912. [CrossRef]

43. Gherboudj, I.R.; Magagi, M.; Goïta, K.; Berg, A.A.; Toth, B.; Walker, A. Validation of SMOS data over agricultural and boreal forest areas in Canada. IEEE Trans. Geosci. Remote Sens. 2012, 50, 1623-1635. [CrossRef]

(C) 2017 by the authors. Licensee MDPI, Basel, Switzerland. This article is an open access article distributed under the terms and conditions of the Creative Commons Attribution (CC BY) license (http:/ / creativecommons.org/licenses/by/4.0/). 